\title{
Commentary: Proinflammatory role of blister fluid-derived exosomes in bullous pemphigoid
}

\author{
Yangchun Liu and Li Li* \\ Department of Dermatology, Peking Union Medical College Hospital, Peking Union Medical College and Chinese Academy of \\ Medical Sciences, Beijing, China
}

Keywords: exosome, bullous pemphigoid, skin disorder, immunology, inflammation

\section{A Commentary on}

Proinflammatory role of blister fluid-derived exosomes in bullous pemphigoid

by Fang, H., Shao, S., Jiang, M., Dang, E., Shen, S., Zhang, J., et al. (2018). J. Pathol. 245, 114-125. doi: 10.1002/path.5061

\section{OPEN ACCESS}

Edited by:

Winston Patrick Kuo,

Harvard University, United States

Reviewed by:

Howard A. Young,

National Cancer Institute at Frederick

United States

*Correspondence:

$\mathrm{Li} \mathrm{Li}$

lilipumch2007@sina.com

Specialty section:

This article was submitted to

Autoimmune and Autoinflammatory

Disorders,

a section of the journal

Frontiers in Immunology

Received: 13 April 2020

Accepted: 09 June 2020

Published: 16 July 2020

Citation:

Liu Y and Li L (2020) Commentary:

Proinflammatory role of blister

fluid-derived exosomes in bullous

pemphigoid.

Front. Immunol. 11:1506

doi: 10.3389/fimmu.2020.01506

\section{INTRODUCTION}

Extracellular vesicles (EVs) are small membranous structures comprised of lipid bilayers. They can be secreted into several biofluids including urine, plasma, saliva, cerebrospinal fluid, synovial fluid, and breast milk (1). Exosomes and microparticles comprise the two major populations of EVs and differ from one another mainly by size and mechanism of generation. Exosomes are EVs $\sim 30-$ $100 \mathrm{~nm}$ in diameter. They are secreted by many immune and non-immune cell types including $\mathrm{T}$ cells, B cells, dendritic cells, and macrophages (2). They contain a wide array of biological materials including proteins, lipids, transcription factors, RNA, and DNA, and enable cell-to-cell communication by transporting their cargo and delivering it to target cells (3). Exosomes can mediate immune stimulation and suppression via antigen presentation, $\mathrm{T}$ cell activation, and antiinflammatory activity (2). Exosome microRNAs can be used as putative diagnostic biomarkers to distinguish autoimmune diseases such as systemic lupus erythematous, rheumatoid arthritis, and dermatomyositis (4).

Bullous pemphigoid (BP) is the most common subepidermal autoimmune blistering disease of the skin (5). The non-collagenous 16A (NC16A) domain of BP180 and the C-terminal domain of BP230 are the major epitopes of BP. Both are hemidesmosome proteins, which are structural components of the hemidesmosomes that connect basal keratinocytes with the basement membrane zone (6). Binding of autoantibodies to hemidesmosome proteins causes degradation of the basement membrane zone and blister formation. This is accompanied by the activation of inflammatory cells (such as eosinophils, neutrophils, and mast cells) and cytokine production [such as interleukins and CC-motif chemokine ligands (CCLs)]. Fang et al. assessed the potential roles of exosomes in the inflammatory processes associated with BP using mass spectrometry. They detected the production of proinflammatory molecules, including interleukin (IL)-6, tumor necrosis factor (TNF)- $\alpha$, and CXC-motif chemokine ligand (CXCL)- 8 , in cell-free supernatants of exosome-stimulated keratinocytes. 


\section{DISCUSSION}

\section{The Mechanism of EV Interaction With Target Cells}

Numerous studies have assessed the interaction of exosomes or EVs with target cells by fluorescence microscopy and flow cytometry. EVs interact with cells through several mechanisms (7). They secrete mediators that bind to receptors expressed on target cells, or may interact with target cells via direct membrane contact. This interaction causes the activation of different signal transduction pathways in target cells $(1,8,9)$. Fang et al. (10) used fluorescence microscopy to demonstrate that exosomes derived from BP patient blister fluid were internalized by keratinocytes and subsequently activated ERK1/2 and STAT3 signaling.

\section{Inflammatory Events Involved in BP}

Many inflammatory molecules have been postulated to play a role in the activity and intensity of BP. The concentrations of cytokines such as IL-1 $\beta$, TNF- $\alpha$, IL-5, IL-6, IL-8, IL-10, IL-15, IL-17, IL-23, and IL-31, and chemokines such as eotaxin-1 (CCL11) and eotaxin-3 (CCL26) are elevated in the sera and blister fluids of BP patients (11-15). Inflammatory proteins such as eosinophil cationic protein, major basic protein, and heat shock protein 90 also contribute to the BP inflammatory reaction $(16,17)$. Fang et al. (10) detected production of the proinflammatory molecules IL6 , TNF- $\alpha$, and CXCL- 8 following the incubation of blister fluid-derived exosomes with primary human keratinocytes. Other inflammatory molecules may be detected after the stimulation of keratinocytes with exosomes, which may help us further demonstrate the role of exosomes in BP inflammatory processes.

\section{The Potential Role of Exosomes in BP}

Fang et al. (10) also conducted proteomic analyses of exosome contents and detected antibody fragments. Based on their findings, we speculate that exosomes may transport the pathogenic autoantibodies associated with BP including antiBP180 and anti-BP230 antibodies. Following internalization, the autoantibodies carried by exosomes may be released to stimulate immune responses. Many studies have demonstrated

\section{REFERENCES}

1. Turpin D, Truchetet ME, Faustin B, Augusto JF, Contin-Bordes C, Brisson A, et al. Role of extracellular vesicles in autoimmune diseases. Autoimmun Rev. (2016) 15:174-83. doi: 10.1016/j.autrev.2015.11.004

2. Tan L, Wu H, Liu Y, Zhao M, Li D, Lu Q. Recent advances of exosomes in immune modulation and autoimmune diseases. Autoimmunity. (2016) 49:357-65. doi: 10.1080/08916934.2016.1191477

3. Selmaj I, Mycko MP, Raine CS, Selmaj KW. The role of exosomes in CNS inflammation and their involvement in multiple sclerosis. J Neuroimmunol. (2017) 306:1-10. doi: 10.1016/j.jneuroim.2017.02.002

4. Zhu $\mathrm{T}$, Wang $\mathrm{Y}$, Jin $\mathrm{H}$, Li $\mathrm{L}$. The role of exosome in autoimmune connective tissue disease. Ann Med. (2019) 51:1018. doi: 10.1080/07853890.2019.1592215.

5. Amber KT, Murrell DF, Schmidt E, Joly P, Borradori L. Autoimmune subepidermal bullous diseases of the skin and mucosae: clinical features, that microparticles carry autoantigens, but few have cataloged the full immunological components of exosomes. The mass spectroscopy analyses conducted by Fang et al. did not detect antigen fragments targeted by BP-associated autoantibodies such as BP180 or BP230 (10). However, it remains to be determined whether exosomes derived from other body fluid, such as plasma and urine, contain autoantigens or related proteins.

\section{CONCLUSION}

We commend the work of Fang et al. (10) for demonstrating the inflammatory role of blister fluid-derived exosomes in the pathogenesis of BP. Multiple studies have assessed the potential roles of exosomes in the pathogenesis of autoimmune diseases such as systemic lupus erythematosus, dermatomyositis, and rheumatoid arthritis. However, no study had investigated the inflammatory role of exosomes in BP pathogenesis. Continued research into the biology and functions of exosomes may facilitate the discovery of new diagnostic biomarkers and contribute to the development of new therapeutic agents for BP.

\section{AUTHOR CONTRIBUTIONS}

YL wrote the manuscript. LL edited the manuscript. All authors contributed to the article and approved the submitted version.

\section{FUNDING}

This work was supported by the National Key Research and Development Program of China Grant No. 2016YFC0901500, National Natural Science Foundation of China (81972945), and Milstein Medical Asian American Partnership Foundation and Education Reform Projects of Peking Union Medical College (2016zlgc0106).

\section{ACKNOWLEDGMENTS}

We thank Sarah Williams, Ph.D., from Liwen Bianji, Edanz Group China (www.liwenbianji.cn), for editing the English text of a draft of this manuscript. diagnosis, and management. Clin Rev Allergy Immunol. (2018) 54:2651. doi: 10.1007/s12016-017-8633-4

6. Bagci IS, Horvath ON, Ruzicka T, Sardy M. Bullous pemphigoid. Autoimmun Rev. (2017) 16:445-55. doi: 10.1016/j.autrev.2017.03.010

7. Colombo M, Raposo G, Thery C. Biogenesis, secretion, and intercellular interactions of exosomes and other extracellular vesicles. Annu Rev Cell Dev Biol. (2014) 30:255-89. doi: 10.1146/annurev-cellbio-101512-1 22326

8. Skokos D, Botros HG, Demeure C, Morin J, Peronet R, Birkenmeier $\mathrm{G}$, et al. Mast cell-derived exosomes induce phenotypic and functional maturation of dendritic cells and elicit specific immune responses in vivo. J Immunol. (2003) 170:3037-45. doi: 10.4049/jimmunol.170. 6.3037

9. Admyre C, Johansson SM, Paulie S, Gabrielsson S. Direct exosome stimulation of peripheral human T cells detected by ELISPOT. Eur J Immunol. (2006) 36:1772-81. doi: 10.1002/eji.200535615 
10. Fang $H$, Shao S, Jiang $M$, Dang $E$, Shen $S$, Zhang J, et al. Proinflammatory role of blister fluid-derived exosomes in bullous pemphigoid. J Pathol. (2018) 245:114-25. doi: 10.1002/pat h.5061

11. Ameglio F, D'Auria L, Bonifati C, Ferraro C, Mastroianni A, Giacalone B. Cytokine pattern in blister fluid and serum of patients with bullous pemphigoid: relationships with disease intensity. Br J Dermatol. (1998) 138:611-4. doi: 10.1046/j.1365-2133.1998.0 2169.x

12. Fang $\mathrm{H}$, Shao $\mathrm{S}$, Cao $\mathrm{T}$, Lei J, Dang $\mathrm{E}$, Zhang J, et al. Increased expression of NLRP3 inflammasome components and interleukin-18 in patients with bullous pemphigoid. J Dermatol Sci. (2016) 83:11623. doi: 10.1016/j.jdermsci.2016.04.009

13. Bonciani D, Quintarelli L, Del Bianco E, Bianchi B, Caproni M. Serum levels and tissue expression of interleukin31 in dermatitis herpetiformis and bullous pemphigoid. $J$ Dermatol Sci. (2017) 87:210-2. doi: 10.1016/j.jdermsci.2017. 04.008

14. Plee J, Le Jan S, Giustiniani J, Barbe C, Joly P, Bedane C, et al. Integrating longitudinal serum IL-17 and IL-23 follow-up, along with autoantibodies variation, contributes to predict bullous pemphigoid outcome. Sci Rep. (2015) 5:18001. doi: $10.1038 /$ srep 18001
15. Gunther C, Wozel G, Meurer M, Pfeiffer C. Up-regulation of CCL11 and CCL26 is associated with activated eosinophils in bullous pemphigoid. Clin Exp Immunol. (2011) 166:145-53. doi: 10.1111/j.1365-2249.2011.04464.x

16. Amber KT, Valdebran M, Kridin K, Grando SA. The role of eosinophils in bullous pemphigoid: a developing model of eosinophil pathogenicity in mucocutaneous disease. Front Med. (2018) 5:201. doi: 10.3389/fmed.2018.00201

17. Tukaj S, Kleszczynski K, Vafia K, Groth S, Meyersburg D, Trzonkowski $\mathrm{P}$, et al. Aberrant expression and secretion of heat shock protein 90 in patients with bullous pemphigoid. PLoS ONE. (2013) 8:e70496. doi: 10.1371/journal.pone.0070496

Conflict of Interest: The authors declare that the research was conducted in the absence of any commercial or financial relationships that could be construed as a potential conflict of interest.

Copyright (c) $2020 \mathrm{Liu}$ and Li. This is an open-access article distributed under the terms of the Creative Commons Attribution License (CC BY). The use, distribution or reproduction in other forums is permitted, provided the original author(s) and the copyright owner(s) are credited and that the original publication in this journal is cited, in accordance with accepted academic practice. No use, distribution or reproduction is permitted which does not comply with these terms. 